\title{
Energy Connections and Misconnections across Chemistry and Biology
}

Kathryn P. Kohn, ${ }^{+*}$ Sonia M. Underwood, ${ }^{*}$ and Melanie M. Cooper ${ }^{\dagger}$

${ }^{t}$ Department of Chemistry, Michigan State University, East Lansing, MI 48824-1322; 'Department of Chemistry \& Biochemistry and STEM Transformation Institute, Florida International University, Miami, FL 33199-2516

\begin{abstract}
Despite the number of university students who take courses in multiple science disciplines, little is known about how they connect concepts between disciplines. Energy is a concept that underlies all scientific phenomena and, as such, provides an appropriate context in which to investigate student connections and misconnections across disciplines. In this study, university students concurrently enrolled in introductory chemistry and biology were interviewed to explore their perceptions of the integration of energy both within and across the disciplines, and how they attempted to accommodate and reconcile different disciplinary approaches to energy, to inform future, interdisciplinary course reform. Findings suggest that, while students believed energy to be important to the scientific world and to the disciplines of biology and chemistry, the extent to which it was seen as central to success in their courses varied. Differences were also apparent in students' descriptions of the molecular-level mechanisms by which energy transfer occurs. These findings reveal a disconnect between how energy is understood and used in introductory science course work and uncovers opportunities to make stronger connections across the disciplines. We recommend that instructors engage in interdisciplinary conversations and consider the perspectives and goals of other disciplines when teaching introductory science courses.
\end{abstract}

Energy has long been identified as central to a robust understanding of science. In the Framework for K-12 Science Education: Practices, Crosscutting Concepts, and Core Ideas (referred to as the Framework in this paper), it is referred to as both a disciplinary core idea in the physical and life sciences and a crosscutting concept (National Research Council [NRC], 2012). However, energy is an elusive concept not easily defined by experts, let alone students. As Richard Feynman famously wrote, "It is important to realize that in physics today, we have no knowledge what energy is" (Feynman et al., 1977, 4.1 What is energy? section, para. 5). But from an early age, students hear the word "energy" used in colloquial language, and the intuitive ideas they develop are not always productive for constructing a meaningful and useful scientific framework (Watts, 1983; Goldring and Osborne, 1994; Barak et al., 1997; Papadouris et al., 2008; Chen et al., 2014; Nordine, 2015). This is particularly problematic, because understanding energy is vital to developing a robust understanding of concepts both within and across science disciplines. In chemistry, all processes are associated with changes in energy, from the macroscopic observations in a lab to the molecular-level interactions that underpin them. Likewise, all biological systems rely on large inputs of energy to maintain order and function, and students are taught to trace this energy through ecosystems and the mechanisms by which it is captured, processed, and stored in organisms.

No matter the disciplinary context, the underlying energy concepts should be the same. However, the ways in which energy is approached in introductory biology and chemistry courses may seem (at best) superficially similar to students. Variations in scale (e.g., macroscopic vs. molecular), disciplinary system (e.g., organismal vs. solutions chemistry), and perspective (e.g., thermodynamic vs. kinetic) may mask the
Jennifer Loertscher, Monitoring Editor Submitted August 11, 2017; Revised October 6, 2017; Accepted October 16, 2017

CBE Life Sci Educ March 1, 2018 17:ar3 DOI:10.1187/cbe.17-08-0169

*Address correspondence to: Kathryn P. Kohn (pariskat@msu.edu).

(c) 2018 K. P. Kohn et al. CBE-Life Sciences Education @ 2018 The American Society for Cell Biology. This article is distributed by The American Society for Cell Biology under license from the author(s). It is available to the public under an Attribution-Noncommercial-Share Alike 3.0 Unported Creative Commons License (http:// creativecommons.org/licenses/by-nc-sa/3.0). "ASCB ${ }^{\circledR "}$ and "The American Society for Cell Biology ${ }^{\circledR "}$ are registered trademarks of The American Society for Cell Biology. 
similarities that underlie these disciplinary approaches and hinder students' ability to transfer their understanding between courses. To facilitate the meaningful learning of energy concepts and the transfer of such learning across disciplinary boundaries, students need to be given scaffolded opportunities to recognize the similarities and reconcile the differences between how we talk about energy in different disciplines and contexts. In this paper, we investigate how students who are concurrently enrolled in both introductory chemistry and biology courses at the university level perceive the integration of energy within each discipline and across the two disciplines, and how they attempt to accommodate and reconcile different disciplinary approaches to energy, for the purpose of informing future, interdisciplinary course reform.

\section{MEANINGFUL LEARNING AND KNOWLEDGE TRANSFER}

Arguably, one of the goals of education is for students to develop a coherent and connected body of knowledge that can be applied in new contexts. To do so, students must engage in meaningful learning (as opposed to rote learning) through the integration of new knowledge with that which they have already learned (Ausubel, 1968; Novak, 1977, 2002). This requires the learner to "consciously and deliberately choose to relate new knowledge to relevant knowledge the learner already knows in some nontrivial way" (Novak, 1998, p. 23). However, for this to occur, the student must already possess appropriate, relevant prior knowledge and perceive the new material as both important and connected to that prior knowledge (Ausubel, 1968; Novak, 1998). Meaningful learning and knowledge transfer are similar, in that they both consider "the impact of prior experience upon current learning" (Ausubel, 1968, p. 129).

The mainstream cognitive perspective on knowledge transfer has traditionally assessed whether the learner can carry over a predetermined piece of knowledge from a learning task to a transfer task (Singley and Anderson, 1989; Anderson et al., 1996; Lobato, 2006; Wagner, 2010). Education researchers are particularly interested in situations of far transfer, that is, where the transfer task is situated in a new and different context from the learning task. However, the term "far transfer" has been arguably ill-defined, resulting in a body of literature in which researchers have come to a variety of conclusions regarding whether and when knowledge transfer occurs (Detterman, 1993; Halpern, 1998; Barnett and Ceci, 2002).

Lobato (2006) has argued that, while some have approached this as a methodological or organizational problem (Novick, 1988; Perkins and Salomon, 1988; Butterfield and Nelson, 1991; Mayer, 1999; Barnett and Ceci, 2002; Fortus et al., 2005), such solutions do not address critiques regarding the traditional conceptualization of transfer as a passive application of knowledge (Lave, 1988; Greeno, 1997; Beach, 1999, 2003; Bransford and Schwartz, 1999; Packer, 2001; Lobato, 2003; Tuomi-Gröhn and Engeström, 2003). Carraher and Schliemann (2002, p. 22) have argued that transfer should be abandoned as a research construct, because "if we endorse the idea of transfer, we subscribe to questionable beliefs about knowledge." However, other researchers have attempted to redefine knowledge transfer to align with accepted theories of learning. Two such alternative perspectives on knowledge transfer are actor-oriented transfer (Lobato, 2003, 2012) and preparation for future learning (Bransford and Schwartz, 1999; Schwartz and Martin, 2004). Rather than assessing whether a predefined strategy or principle is transferred between two tasks that the researcher views as structurally similar, these perspectives consider any ways in which learners' prior experiences shape their engagement in the transfer task (Lobato, 2006; Marton, 2006). Additionally, preparation for future learning considers how a past learning experience may enhance a student's ability to engage with and learn from a future one (Bransford and Schwartz, 1999; Schwartz and Martin, 2004).

Chi and VanLehn (2012) have hypothesized that the results of many of the early two-problem transfer studies could be better explained by a lack of deep initial learning rather than a failure to transfer. Similarly, meaningful learning emphasizes that the "quantity and quality" of existing knowledge structures (Novak, 2002, p. 522) and "such organizational properties of the learner's subject matter knowledge as clarity, stability, generalizability, inclusiveness, cohesiveness, and discriminability" (Ausubel, 1968, p. 129) will determine transfer success.

The conditions of meaningful learning indicate ways in which instructional practices can encourage deep learning experiences such that students can more successfully transfer their knowledge to new contexts (Ausubel, 1968; Novak, 2002). While the extent to which meaningful learning occurs depends on the choices and past learning experiences of the student, instructors can promote and facilitate more meaningful learning through careful consideration of how curricula are organized and by making clear and explicit connections among related ideas (Ausubel, 1960, 1968; Novak, 1977). Further, assessment practices can encourage students to learn meaningfully by limiting their ability to be successful through memorization alone (Novak, 1977). While meaningful learning and knowledge transfer are often considered within the context of a single course or disciple, we believe that such theories can be broadened to consideration of course sequences.

There is little work on how students transfer knowledge from one discipline to another (which we might certainly characterize as far transfer). As such, the goal of the following study was to characterize the current state of alignment between the introductory biology and chemistry courses from the learner's perspective in an effort to facilitate future, interdisciplinary course reforms that support meaningful learning and the transfer of said learning across disciplinary boundaries.

\section{DEFINING AND DISCUSSING ENERGY-A REVIEW OF} THE LITERATURE

For decades, instructors and researchers have considered how best to improve the teaching and learning of energy. Early research at the $\mathrm{K}-12$ level focused on describing the intuitive ideas and alternative conceptions of students (Watts, 1983; Goldring and Osborne, 1994; Barak et al., 1997; Papadouris et al., 2008). More recently, focus has shifted to proposing and evaluating new teaching approaches (Pintó et al., 2005; Batiza et al., 2013; Fortus et al., 2015) and describing how scientific understanding develops across grade levels through research on learning progressions (Liu and McKeough, 2005; Lee and Liu, 2010; Jin and Anderson, 2012; Neumann et al., 2013). At the high school and undergraduate levels, as students' science course work begins to become more discipline specific, the scope of the research narrows. Studies explore 
student conceptions surrounding discrete topics such as enthalpy (Carson and Watson, 1999; Nilsson and Niedderer, 2014) or photosynthesis (Brown and Schwartz, 2009; Parker et al., 2012), as we will discuss in more detail later. Recent approaches to the development of more coherent curricula have not only brought the concept of energy to the forefront of science education, elevating it from an isolated topic to a core idea that forms the foundation for understanding many different phenomena, but have also emphasized the interdisciplinary role it plays as a lens through which all science topics can be considered (American Association for the Advancement of Science [AAAS], 2011; NRC, 2012).

\section{The Interdisciplinary Nature of Energy}

The Framework designates energy as one of four disciplinary core ideas for physical science; it also appears as part of the ecosystems disciplinary core idea for life sciences and is a crosscutting concept: "energy and matter: flows, cycles, and conservation" (NRC, 2012). There is no other idea that transcends disciplinary boundaries in this way. However, the ways that energy is integrated into each discipline are different because of the nature of the discipline, the history and culture under which it arose, and perhaps most importantly, a lack of interdisciplinary understanding about how energy might be integrated in a more coherent manner.

Consider the complexity of navigating various definitions of energy encountered in multiple science contexts. Terminology and symbology can vary between disciplines even when referring to the same concept (e.g., $\mathrm{U}, \mathrm{V}$, and $\mathrm{E}_{\mathrm{p}}$ are used to represent potential energy in various contexts). Many of the scientific terms we use (e.g., energy, heat, potential, and work) have strikingly similar and yet significantly different meanings when encountered in everyday speech (Nordine, 2015). One of the most common definitions, energy as the capacity to do work (Energy, 2000) is problematic for several reasons. For one, it relies on circular reasoning, as work is commonly accepted to be one of the means through which energy is transferred (Lehrman, 1973; Sexl, 1981; Trumper, 1990a,b, 1991; Hecht, 2007). In physics texts, this definition is almost exclusively associated with mechanical energy, which does not provide students with a satisfactory connection to topics involving thermal and radiant energy (Sexl, 1981). To make matters worse, chemistry and biology textbooks often use this definition without even defining work (Lancor, 2014) and despite the fact that mechanical energy is rarely useful in the context of these courses (Gayford, 1986; Kaper and Goedhart, 2002).

The situation is even further complicated by the many "forms" of energy introduced to students over the course of their education. In this paper so far, we have mentioned mechanical, thermal, radiant, and potential energy. Instead of this multiplicity of different types of energy, the Framework lays out a coherent approach in which energy can be considered as either that of motion (kinetic energy) or stored in fields (potential energy; NRC, 2012), which gives educators a way to help students construct an understanding of energy that is consistent and transferable across disciplines. For example, mechanical energy means little in chemistry or biology, and chemical energy rarely makes an appearance in physics courses, but kinetic and potential energy can be used to understand all the forms of energy that are typically presented to students. In addition, this coherent approach provides a way to describe the mechanisms of energy transfer via molecular-level collisions and reaction coupling.

While it may seem obvious to experts that the energy discussed in one course is no different from the energy discussed in any other, this is not always apparent to students (Jewett, 2008; Cooper and Klymkowsky, 2013b). How we talk and think about energy is context dependent. Energy is considered to be an analytical tool that is applied differently depending on the scale we are exploring and to answer different disciplinary questions (Nordine, 2015). In one of the few studies to explore energy in multiple disciplines at the university level, Park and Liu (2016) developed an instrument of two-tiered questions (multiple choice followed by short-answer justification) to assess students' conceptions of energy in four disciplines (i.e., biology, chemistry, environmental science, and physics). The authors found that students who understood energy in one disciplinary context were more likely to understand it in another, but the study did not address how understanding of energy transferred between disciplines. Lancor (2014) found that students from chemistry, biology, and physics courses used the same underlying metaphors (e.g., energy as a substance that can be carried) and that choice of metaphor was more dependent on attributes of the context (e.g., scale) rather than the disciplinary setting. Both studies addressed student understanding of energy in multiple disciplines, but not how that understanding is transferred and used.

Another area of research has been situated in the context of interdisciplinary courses such as the NEXXUS/Physics project, which redesigned introductory physics for biologists (Dreyfus, 2014; Dreyfus et al., 2014; Geller, 2014; Geller et al., 2014; Redish et al., 2014). Geller (2014) reports that some NEXXUS/ Physics students described physics and biology being in a hierarchical relationship based on scale, complexity, or level of abstraction. One student described the order in terms of increasing system complexity from physics to chemistry to biology. This student believed the jump from physics to biology to be too large and felt that she lacked the connections between physics and chemistry that were needed along the way.

\section{Energy and Biology}

Before considering energy as it pertains to biological systems, we must first define the scope of our study. Biologists can study anything from the replication of DNA to the biodiversity of the entire planet. Because the students who are the focus of this study were enrolled in a cell and molecular biology course, we will focus on the cell and molecular level, the components and processes of which are strongly tied to chemical structure and mechanism.

Biology instructors and researchers have long been concerned with students' ability (or lack thereof) to understand and integrate their knowledge of energy in biology with what they learn in physical science classrooms (Gayford, 1986; Barak et al., 1997; Chabalengula et al., 2012). Understanding the energy transfers involved in cellular respiration and photosynthesis is particularly difficult for both teachers and students (Wilson et al., 2006; Brown and Schwartz, 2009; Parker et al., 2012; Batiza et al., 2013). Batiza et al. (2013) argues that this is because learners must have a solid understanding of physical science principles such as atomic structure, electrostatic attractions, and the energy changes associated with the formation and breaking of bonds and interactions - a concept that is 
notoriously problematic for students, as discussed later (Storey, 1992; Boo, 1998; Barker and Millar, 2000; Teichert and Stacy, 2002; Galley, 2004). On a related note, Garvin-Doxas and Klymkowsky (2008) found that many student difficulties in cell and molecular biology could be traced to problematic understanding of the stochastic nature of biological processes. Few students recognize the relevance of random molecular motion and energy transfer via collisions, which has widespread consequences in all science disciplines (Garvin-Doxas and Klymkowsky, 2008). It is the perpetual motion of atoms and molecules that leads to the necessary collisions that allow energy transfer and change to occur. However, little research has explored student understanding of stochasticity in biology despite the disciplinary relevance. This may be due to the instructional emphasis on Gibbs free energy and reaction coupling in introductory cell and molecular biology courses.

\section{Energy and Chemistry}

The concept of energy is also fundamental to developing an understanding of chemical phenomena. However, it should be noted that, in most college-level chemistry courses, the idea of energy as an overarching concept may not be explicit. For example, to understand diverse phenomena such as bonding and intermolecular forces, ionization energy, phases changes, and solution formation, one must consider the associated energy changes. And yet, at the introductory college level, discussions of energy tend to be concentrated in two discrete chapters on thermochemistry and thermodynamics, and even the national-level transformation efforts (College Board, 2014; Holme et al., 2015) appear to limit discussion of energy to these two topics. Therefore, it is not surprising that most of the research on student understanding of energy at the college level focuses on thermodynamics. A review of the thermodynamics education literature by Bain et al. (2014) found that most studies focused on student conceptions, particularly relating to spontaneity, equilibrium, and the laws of thermodynamics (Banerjee, 1995; Carson and Watson, 1999, 2002; Greenbowe and Meltzer, 2003; Hadfield and Wieman, 2010; Nilsson and Niedderer, 2012, 2014).

\section{Making and Breaking Bonds: Chemical Potential Energy}

While most of the research on energy in chemistry is focused on thermochemical ideas, it is in fact an understanding of potential energy that is necessary for students to understand chemical bonding. Despite this, there is considerably less research on how students understand potential energy in the context of chemistry. Becker and Cooper (2014) identified three ideas (i.e., energy storage, capability, and stability) that chemistry students use to describe potential energy at the atomic-molecular level. While each of these ideas could be productively applied to reason about atomic and molecular interactions, more often students offered intuitive or incorrect interpretations rather than scientifically accurate ones. Only approximately $10 \%$ of students in a general chemistry course could provide appropriate, useful ideas about potential energy.

Understanding potential energy is crucial, as it is central to the relationship between energy and bond breaking and formation. While students are often able to identify whether a process requires or releases energy at the macroscopic level from the resultant temperature change (i.e., thermochemistry), the underlying mechanism of this energy change is fraught with difficulty for students. The idea that breaking bonds releases energy is a commonly held alternative conception among both high school and undergraduate students (Storey, 1992; Boo, 1998; Barker and Millar, 2000; Teichert and Stacy, 2002; Galley, 2004) and has even been noted among chemistry graduate students (Gonzales, 2011). These problematic ideas may stem from students' early experiences with energy in everyday life (e.g., energy content in food) and later be reinforced in courses in which energy is discussed as being stored in molecules (Storey, 1992; Cooper and Klymkowsky, 2013b). Indeed, there are a number of instructional materials that describe ATP as having "high-energy bonds" (Cell Energy and Cell Functions, n.d.), even though many instructors and researchers have argued that this is misleading and can cause confusion when students attempt to make connections between what is taught in the physical and life sciences (Gayford, 1986; Storey, 1992; Galley, 2004). Villafañe et al. (2011) have shown that this misconception persists into biochemistry and found that $74 \%$ of students were able to correctly answer all three bond energy questions during a posttest assessment (as opposed to $4 \%$ on the pretest), which they attributed to the use of a process-oriented guided-inquiry learning activity on high-energy compounds (Loertscher and Minderhout, 2010). These promising results suggest that students at all education levels could benefit from explicit consideration of energy topics. Nevertheless, the persistence of confusions about bond energies, is a profound example of why it is so necessary that we address energy with a coherent, interdisciplinary perspective.

\section{PURPOSE OF THE STUDY}

Typically, more than half of the students who take two semesters of general chemistry are life science or pre-professional majors, and chemistry is often listed as a prerequisite (or at least a co-requisite) for introductory biology, presumably so students can use their knowledge of chemical reactions and molecular interactions to think about biological systems. Little is known about how students use and transfer knowledge across disciplinary boundaries, and therefore, to inform future, interdisciplinary reform, this study was designed to characterize the current alignment of the introductory chemistry and biology courses from the learner's perspective by investigating whether students do in fact recognize connections between the content and to determine whether they believe the connections to be useful. When this study began, the introductory science courses were at various stages of a collaborative transformation process (Cooper et al., 2015). Therefore, the data we present should be considered in the context of courses that were attempting to develop a coherent approach across the disciplines. The ultimate goal of the study described herein was to identify opportunities for stronger connections between the courses and to understand potential barriers in developing those connections in an effort to facilitate course reform focusing on making explicit interdisciplinary connections.

\section{METHODS}

\section{Setting and Participants}

This study was set at a large, public research university in the Midwest where the average student had an ACT composite score of 24-29. The student body includes $18.7 \%$ students from 


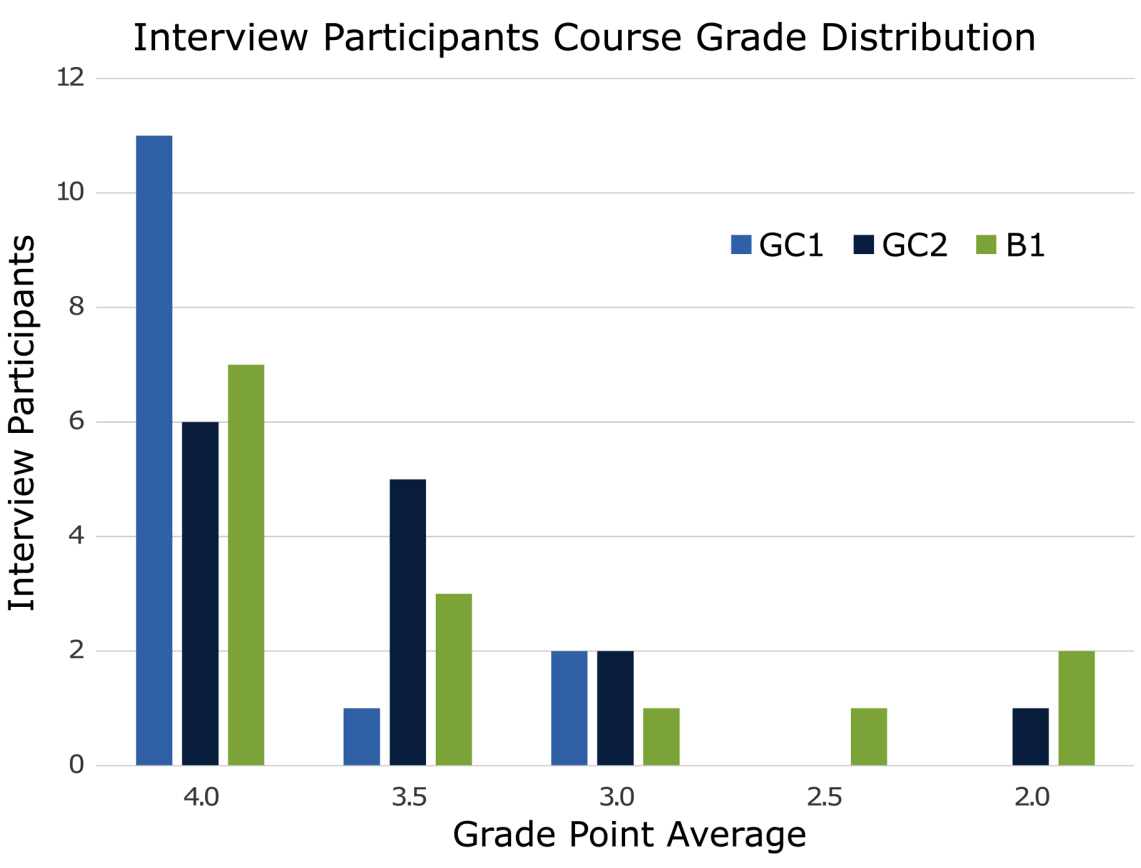

FIGURE 1. The distribution of interview participants' course grade point averages. B1, introductory cell and molecular biology course; GC1, general chemistry 1; GC2, general chemistry 2.

underrepresented groups and $14.4 \%$ international students. At this university, general chemistry for science, technology, engineering, and mathematics (STEM) students is taught as a two-semester sequence (GC1 and GC2). Lecture sections are 350-450 students in size and include a required 1-hour recitation section. About 35\% of students who take GC1 go on to GC2 at this institution, with most of these students pursuing majors related to the biological sciences. Only students who had taken both GC1 and GC2, in the Fall 2014 and Spring 2015 semesters, respectively, were included in this study, because we wanted them to share a recent experience that would allow them to provide informed commentary.

It is important to note that these students were taught using a transformed general chemistry curriculum-Chemistry, Life, the Universe, and Everything (CLUE)-designed to help students build a more sophisticated and cohesive understanding of four core ideas, one of which is energy (Cooper and Klymkowsky, 2013a,b). It is intended to address the needs of the majority of general chemistry students including life science and preprofessional majors and uses biological phenomena to illustrate the underlying chemistry content. Over time, the energy progression within the curriculum has been iteratively improved to help students connect to their prior knowledge of forces and energy by starting with potential and kinetic energy in the context of atomic interactions explicitly discussing the relevance of collisions and the energy changes associated with bond breaking/formation (Cooper and Klymkowsky, 2013b; Cooper et al., 2014). This course plays an integral role in the context of this study.

The first introductory biology course (B1), taken primarily by STEM majors, focuses on cell and molecular biology. While students can take this course concurrently with GC1, it is not common for students to do so. Lecture sections range from 150 to 250 students and present seven core ideas that were negotiated by the faculty, using Vision and Change as the starting point, which are introduced at the beginning of the semester. One of these core ideas is matter and energy. At the beginning of each unit, the applicable core ideas are described again in the context of the upcoming material. All lecture sections of B1 use a commercial textbook and homework system (Mason et al., 2015) to provide a common resource and approach. The students who participated in this study were enrolled in the same lecture section of B1, the instructor of which was aware of this study and provided helpful guidance to the researchers to contextualize the information being taught. One of the authors attended lectures of both this course and the chemistry course from which participants were selected.

A call for participants was made in the GC2 courses during the last 2 weeks of the Spring 2015 semester, offering a small amount of extra credit as compensation for participation. The first 14 volunteers who met the qualifications were included in the study. That is, they had taken GC1 in Fall 2014 and both GC2 and B1 in Spring 2015, were in CLUE lecture sections for both GC1 and GC2, and had taken the preselected B1 lecture section. The other 385 volunteers were given an alternate activity to complete for extra credit. Of the 14 participants, nine were female and five were male; all were interested in pursuing careers related to biological science or the health professions. Twelve of the students were finishing their first year; the other two were finishing their second year. Of the 14 students, eight earned a 3.5 or above in GC1, GC2, and B1. On average, the interview participants earned a 3.8 GPA in GC1, 3.5 in GC2, and 3.4 in B1. The complete student grade data are presented in Figure 1. All student data presented were gathered with institutional review board approval. Students were notified of their rights as research participants and provided informed consent before participating in the study.

\section{Interview Protocol}

The work presented here was part of a larger interview protocol that probed student perceptions regarding connections between their course content more generally (see Appendix A in the Supplemental Material). Because we were asking students to discuss and connect an entire year of science course work, we designed the protocol to allow time for reflection and discussion of each course before having the students attempt to make connections. Therefore, the protocol began by asking students to brainstorm a list of things they had learned in general chemistry and consider what the big ideas ${ }^{1}$ or take-home messages were for the course. GC1 and GC2 were treated as a single

\footnotetext{
${ }^{1}$ The term "big ideas" was meant to be synonymous with "core ideas" (referred to in educational literature such as the Framework [NRC, 2012]). This term was used because it was familiar to the students from their course experiences.
} 
course sequence throughout the interviews. While instructors had defined core ideas in both GC1/GC2 and B1, students regularly provided their own. After repeating this process for B1, the students were asked to discuss any connections they felt existed between the courses and what, if any, conflicts they perceived between the material discussed.

The second half of the protocol was inspired by the crosscutting concepts of the Framework (referred to as "themes that span chemistry and biology" in the interviews; NRC, 2012). Students were given the opportunity to generate their own themes before being asked about two in particular-energy and the relationship between structure, properties, and function. Students were asked to describe why energy would be considered a theme, how it was discussed in each of their courses, and to describe the relative emphasis and importance of energy in each course. Concepts of energy transfer and energy conservation were explicitly discussed.

\section{Data Collection and Analysis}

The 14 interviews varied in length from 70 to 150 minutes depending on the amount of information provided by the students, who were told that they could terminate the interview at any time. However, all participants had a great deal of information to impart and willingly stayed longer than we had anticipated. Students used a Livescribe pen to create lists of ideas and enhance their descriptions with diagrams and drawings that allowed the audio data to be collected in conjunction with their constructed responses. Additionally, a digital recorder was used as a backup audio source. Data collection and analysis were undertaken from a phenomenographic perspective, as our intention was not to categorize what students do or do not know, but instead to provide a rich description of the various ways that students related their experiences taking introductory chemistry and biology.

The audio data were transcribed verbatim by a professional transcription service and then reviewed and edited for both accuracy and completeness by K.P.K. To gain a holistic understanding of each student interview, the entirety of the transcript was read and summary notes were taken. However, due to the length and depth of the interviews, all references to energy or topics considered by students to relate to energy were excerpted with both context and analysis notes interspersed. The excerpts were then coded by context (i.e., chemistry or biology) and topic (e.g., references to potential or kinetic energy, bonding, cell metabolism). Each topic and context code was treated as a subsection of data and open coded. This allowed the researchers to identify what course topics were being discussed and how discussion of those topics varied by context and by student. The interview protocol followed three lines of questioning: discussion of energy generally within the courses and with respect to the conservation of energy and energy transfer. Ultimately, student discussions of the conservation of energy were found to contain little more than a restatement of the first law of thermodynamics. Therefore, the findings presented herein are limited to discussions of energy (general) and energy transfer. The data were reviewed and discussed iteratively by K.P.K. and M.M.C. to ensure that these areas of discussion were accurately represented by the chosen quotes. While most of the data herein are from the portions of the interviews during which energy was the focus, all discussions of energy were used to inform our analysis. To improve readability, vocal fillers have been removed from the transcript excerpts presented here.

\section{FINDINGS}

Within the two main areas of discussion, we found that 1) students held differing opinions about whether energy would be considered a core idea in their courses, despite describing it as generally important to the scientific world, and 2) descriptions of energy transfer (and particularly the molecular-level mechanisms by which it occurs) were highly context dependent. As students elaborated on their understanding of energy transfer in chemistry and biology, it became clear that many were unaware or confused about how to make connections between their courses, particularly when discussing ideas such as reaction coupling, the relationship between energy and bond breaking and forming, and molecular-level collisions. Additionally, while it was common for the terms "kinetic" and "potential" energy to be discussed in the context of chemistry, this terminology was infrequently used in the context of biology. Together, student discussion of these ideas and the relative necessity of energy within their courses reveal a substantial disconnect between how energy was understood and used in their course work.

\section{Energy as a Core Idea in Chemistry and Biology}

As noted previously, both the Framework and Vision and Change regard energy as a core concept, central to a robust understanding of science (AAAS, 2011; NRC, 2012). Students also recognized the importance of energy to the physical and natural world, stating that energy "gets things started," "drives reactions," or as John put it, "Everything requires energy." These statements are reminiscent of conceptions taught in early science classes, describing energy as a causal necessity, a notion that is at the very least incomplete (Ogborn, 1986, 1990; Lancor, 2014). However, despite their belief in the general importance of energy, opinions varied regarding the relative importance of energy in the general chemistry (GC1/GC2) and cell and molecular biology (B1) courses they were coenrolled in. One of the final energy questions during the interviews was, "Do you think that understanding energy was more important for one course over the other or equally important for both?" Four students felt that understanding energy was equally important in both courses. Nine believed that understanding energy was more important in chemistry. The remaining student, Lida, clarified that energy was "not necessarily less important in bio, but less apparent." In comparison, she said that, in chemistry, "Literally everything that you do I feel like energy is somehow incorporated." Three of the nine students (Daniel, Natalie, and Joseph) went so far as to state that understanding energy was not necessary to their success in B1.

Natalie: I think you can still do well on any biology test that I've taken without really understanding energy and its properties, and I think you would not do well at all if you had no understanding of energy and its properties on any of those chemistry tests-or just in understanding chemistry in general.

Natalie believed that she needed to understand energy not just to be successful in GC1/GC2, but also to develop a strong 
understanding of the content. However, she believed that she could do well on her biology exams without such understanding of energy. It is important to remember that these students were comparing their biology course with a transformed chemistry curriculum that was designed to explicitly focus on four core ideas (one being energy). This is made evident by Daniel's description of energy in GC1/GC2. He recognized that subsequent ideas were built upon energy concepts they had already learned and were therefore more important to understand.

Daniel: In chemistry, in order to succeed and learn the next idea, big concept or whatever you need to know, that you need to know about energy. I think in biology the way we learned it, we didn't necessarily need to, know about energy. I would have liked to, because I think I would have understood it better, but in order to succeed I really don't think we needed it as much in the course.

While Daniel felt that having a better understanding of energy would improve his comprehension of the biology material, he too felt that it was not necessary for the course. As noted earlier, even though energy has been designated as a core idea in B1, the commercial textbook does not explicitly connect the core ideas for students. Differences between how explicitly energy was discussed and connected to other ideas within the two courses led students to believe it was more important for GC1/GC2, as evidenced by Louanne.

Interviewer: Do you think that your understanding of energy was more important for one of your courses over the other? Or equally important in both?

Louanne: In chemistry, it just keeps coming up again, and again, and again. So I feel like it's used for more things ... yeah definitely more in chem, over biology. Just based on the fact that it's brought up more, and I feel like I personally use it, the idea of it more.

In fact, five of the 14 students went on to describe the discussion of energy in B1 as being limited to the metabolism unit. While Lida recognized that ATP was being used as a placeholder, a reference to the energy involved in biological processes, Louanne did not.

Louanne: I know we use energy for the different cycles and stuff like that. But now that we're out of the cycles, we're into DNA replication, and we're not talking about energy anymore.

Lida: When they're talking about DNA synthesis they don't really talk about where the energy comes from to do that, or where the energy goes to do that, it's more so, "Oh, just ATP." Everything just goes back to ATP.

These references to ATP (and therefore, energy) made throughout B1 were not sufficiently explicit for Louanne. And so, because she could more easily recognize the role of energy in GC1/GC2, she believed it to be more important in that course.
We also found that students described various ways in which they could use their understanding of energy in chemistry, such as constructing reaction diagrams and other graphs of Gibbs free energy, or determining the enthalpy of a reaction; however, we did not find any description of how students used their understanding of energy in biology. Instead, students focused on describing metabolic processes and cataloguing the inputs and outputs of those reactions (e.g., the number of ATP molecules required for and produced during glycolysis). Discussions of energy largely occurred at the molecular level, as one might expect from students coenrolled in chemistry and cell and molecular biology. This was particularly apparent when students were discussing energy transfer.

\section{Molecular-Level Descriptions of Energy Transfer} Energy Transfer in Biology-Reaction Coupling. The coupling of ATP hydrolysis to an unfavorable reaction is a vital component of energy transfer in biology. While it is not the only example of reaction coupling in biological systems, it is the most commonly discussed example in introductory biology courses. However, only two students (Ruth and Natalie) discussed reaction coupling in any detail.

Ruth: Energy transfer in biology, I feel like I think more of something being phosphorylated, and how that sort of transfers energy, as opposed to two things colliding ... when you transfer a phosphate group, and that gives off a lot of energy... It can be used as activation energy for something else, and a coupled reaction.

Natalie: It's also hard to understand how the glucose can be converted into ATP if you don't really understand chemistry. And so obviously a lot goes into it, but basically it's like a coupled reaction ... so you need an exergonic reaction in order to have the energy to allow the endergonic reaction to overcome the activation energy.

The ideas that these students are struggling with are complex and often counterintuitive. Natalie implies that the coupling provides energy to overcome the activation energy barrier; in fact, coupling acts to produce a more reactive phosphorylated species so the barrier to reaction is lower. Ruth expanded on this idea by including the transfer of a phosphate group, but neither student could give a coherent explanation of this mechanism.

The level of insight that both Ruth and Natalie provided was unusual. Of the 13 students who discussed ATP, eight indicated that they were unsure about how it worked. In fact, it was not uncommon for students to have incorrect notions about ATP and its role in biological processes. Five students referred to ATP as energy or a form of energy.

Daniel: ATP is a form of energy that, can help a reaction take place... And the way that we were briefly described in biology was that, it was like harnessed energy, and when the bonds were broken, it released energy.

Daniel's description includes an alternative conception (i.e., breaking bonds releases energy) that has been well documented among students at varying stages in their education (Boo, 1998; 
Barker and Millar, 2000; Galley, 2004). While not uncommon among students interviewed for this study, it was exclusively mentioned in the context of their biology content. Of the 12 students who discussed the relationship between energy and the breaking and forming of bonds, every one of them did so correctly in the context of chemistry (i.e., energy is required to break a bond and energy is released when a bond is formed). This is possibly because these concepts are emphasized in the transformed chemistry curriculum. Reports of students in more traditional chemistry curricula indicate more confusion around this topic (Teichert and Stacy, 2002). Unfortunately, this understanding did not seem to transfer well to their studies in biology. Only eight students discussed the energy changes associated with bond breaking/formation in the context of biology; of these students, five felt there was a conflict between what they had learned in chemistry and what they perceived to be the correct relationship in biology. Clarice seemed to recognize this conflict for the first time during her interview.

Clarice: I'm starting to think about this as I was trying to explain it to you because ATP, when the bond's broken, energy is released ... when one of the phosphates is broken off, it releases energy. That's, I think, what's getting me. Because when the bond's broken, it should absorb energy. So I'm getting very confused.

When trying to explain how ATP could provide energy to a reaction, she realized that she was contradicting what she had learned in chemistry. Although she was comfortable with the ideas she had learned in her respective courses, she was unsure how to reconcile them, having never considered it before.

Lida recognized the conflict in the process of studying with a group of friends who were coenrolled in chemistry and biology. Someone proposed a practice question about ATP to which she (and her friends) believed the correct answer would have been different depending on the course she was taking the test in. She found her inability to reconcile these two ideas frustrating.

Lida: I just learned something in two opposite ways... I actually still don't really understand it, to be honest. I don't really know which one's right, if it's ATP produces energy or the phosphate group from the ATP produces the energy when bound to-I think it's the second one, but I'm not really sure... Because I know that everybody who I'm friends with who's in bio and chemistry all knows the same thing, in bio this is right, in chemistry this is right. But then we don't actually know which one's right.

Lida got to the root of the problem without even realizing it. Without an understanding of the setting in which ATP hydrolysis occurs, the only noticeable change is that a phosphate group is broken off. This is because the new bonds being formed are often left out. Daniel also indicated that a lack of context left him unsure of how ATP works.

Daniel: So in glycolysis we said, "Oh, it releases ATP and that gives energy." I know that, okay, ATP, energy. But I'm just not entirely sure how that whole process happens ... the way that we were briefly described in biology was that, [ATP] was like harnessed energy, and when the bonds were broken, it released energy ... in the back of my head I know that that's probably not exactly how ATP works. There has to be something else that's going on, because clearly that's the opposite of what we had learned [in chem].

Daniel was confident in his understanding of the energy change associated with bond breaking and formation based on what he had learned in GC1/GC2: breaking bonds requires energy. This allowed him to recognize that the brief discussions of ATP in biology were missing something. Throughout his interview, he expressed the desire to better understand ATP and how it relates to energy.

If we consider Natalie's explanation of ATP, the potential for misunderstanding seems quite clear. "[ATP is] divided into ADP and phosphate and then that division provides energy for your body since that's an exergonic reaction." Indeed, ATP hydrolysis is an exergonic (thermodynamically favorable) reaction. And students are told that there is a net release of energy that can allow thermodynamically unfavorable reactions to occur through reaction coupling. However, when this reaction is described superficially, as Natalie did (and as is shown in some educational materials [Cell Energy and Cell Functions, n.d.]), it is the breaking of the phosphate bond that is most apparent. Given these two pieces of information, the conclusion that breaking bonds releases energy seems quite logical and self-consistent. Though frustrated and confused, those who recognized the conflict did not believe that B1 was negatively impacted. Daniel described it as a "minor detail" in biology, and the other four students knew what would be considered the correct answer in each course. Consider Priyah:

Priyah: I feel like I can ration [sic] it out both ways, so then, I understand why someone would say either/or, but then I know for biology what [the instructor] wants us to say and then for chemistry what we have to say.

Unable to determine which was correct, Priyah would tailor her response to the course she was in. Despite feeling that they could successfully answer the question for each course, both Lida and Priyah expressed dissatisfaction with their understanding.

In summary, only two students (Ruth and Natalie) mentioned reaction coupling as a mechanism of energy transfer. More commonly, students simply described ATP hydrolysis as providing energy, though they did not know how this happened. Some students could do little more than equate ATP with energy. For instance, Louanne used an analogy to describe how biological processes occur, "Well, we talk about [ATP or GTP] as ... I think of it as coins, at an arcade. You have to put so many in to get the system going." While such an analogy serves to impress upon students that ATP is important and associated with energy input, it is an example of how discussing ATP hydrolysis and reaction coupling only briefly can leave students feeling as Daniel did, that the only takeaway is that ATP has something to do with energy.

It is interesting to note that the term "potential energy," or even "chemical energy" (which is often described as a type of potential energy by instructional materials), was not used by students when describing biological systems at the molecular level. While two students mentioned learning about 
potential energy in biology, only one student applied the term in context.

Simon: We know that energy comes from the things that we eat, the potential energy in food... And we know that the cells can then use that chemical potential energy to create things like kinetic energy or chemical energy to do the things that they need to do.

While Simon's discussion of potential and kinetic energy is almost certainly prior knowledge, he did not go on to use it in the context of the courses he was taking.

In contrast, most of the students interviewed (11 of 14) mentioned learning about potential energy in the context of chemistry, often referencing the potential energy curve that was discussed extensively at the beginning of GC1. Simon: "I just remember drawing the potential energy curve 100,000 times." The simulation ${ }^{2}$ showed how the kinetic and potential energy changed as the distance between two atoms changes.

Aaron: We talk about energy between atoms, coming together. Like if two helium atoms are coming together, we talk about the kinetic energy versus the potential energy of the atoms, like depending on where they're at-if they're close or if they're far. We talk a lot about energy all the time.

The multiple lecture periods spent discussing potential energy and the chance for students to interact with the situation in a variety of ways may have led to a number of the connections students made to other concepts (e.g., stability, energy transformation, conservation of energy). Clarice and Shelly describe features of the simulation that show energy being added or removed from the system through the collision of a third atom.

Clarice: Because in the beginning we talked about the potential energy curve or whatever, and how ... when it was in a stable bond and you put that extra molecule in, it broke up the bond because it was giving it its energy.

Shelly: [...] and the potential energy curve, and they would come together and they would come apart, and then, they would come together, and then something would come collide and take the energy, and they'd stay together.

These descriptions illustrate the relationship between energy and the breaking and forming of bonds. However, both potential and kinetic energy are implicit in these descriptions, through discussion of the stable bond and collisions, respectively. And when explicitly discussing reactions and bonding (topics that were discussed at a later time in GC1/GC2), students favored terms like "Gibbs free energy" or simply "energy." While it is clear that the students interviewed were aware of potential energy in chemistry, they did not appear to be connecting and applying this concept to other ideas in either chemistry or biology.

${ }^{2} \mathrm{http} / /$ virtuallaboratory.colorado.edu/CLUE-Chemistry/LondonDispersionForce/ 1.2-interactions-1.html
Kinetic Energy and Collisions-The Initiation of Energy Transfer. While reaction coupling is the mode of energy transfer most commonly mentioned in introductory biology courses, a reaction would never be initiated if the reactants did not first collide (a mechanism of kinetic energy transfer). However, use of the term "kinetic energy" was absent from students' descriptions of energy transfer in biological systems. This is not entirely surprising, as few biology (or even chemistry) courses discuss the role of collisions in detail. In this way, the CLUE curriculum is different, emphasizing the importance of collisions as the mechanism of kinetic energy transfer throughout the entirety of the course. Most students in this study (10 out of 14) discussed the collisions of atoms and molecules in the context of energy transfer. There were examples of students describing collisions in the context of phenomena (e.g., phase changes) and using them to explain why breaking a bond requires energy. Three students (Natalie, Joseph, and John) went so far as to call collisions a "big idea" of GC1/GC2. While Natalie did not feel that collisions were discussed to the same extent in the second semester, she asserted that they were still at the core of the concepts being discussed (e.g., kinetics, equilibrium):

Natalie: [Collisions are] the underlying reason for a lot of things. So we'll just say, "Okay, well when temperature increases more collisions and therefore that's why this happens," ... that's why the reaction will go faster and that's why it will go in this direction or that direction. So I feel like it still is a huge part of what we're learning ... it's always kind of there in the back of your mind.

Natalie recognized that, even if collisions were not being discussed in detail, they were fundamental to the causal mechanism underlying changes in the direction or rate of a reaction. She was not alone in emphasizing the importance of collisions. Joseph referred to them as the "answer to everything" and Ruth stated that "in order for every action to occur, [the] molecules need to collide and they need to transfer energy to each other." Despite this confidence in their ability to describe the role of collisions within chemistry, only three students (Joseph, Serina, and John) immediately made the connection to biological systems. Consider Louanne's description of energy transfer in biology as compared with chemistry:

Louanne: The transfer of energy? Well, I know we talk about it in chemistry a lot... You have two atoms, and then you add another one. And they collide, and it transfers energy to break it out of that system. Or heating things up, where you have a container of something and you heat the outside. So the atoms are going to start colliding faster and transferring that energy around. In biology, the transfer of energy-I don't know... I know for sure I can relate it to chemistry. But biology, eh, not so much.

While she could discuss collisions when considering the energy transfer involved both in a single interaction and with respect to changes in the macroscopic properties of a material, she was unsure of how to think about energy transfer in biology. When asked to consider it further, Louanne stated that they were more focused on "the breaking down of energy and then building it back up." When encouraged to think about how her 
understanding of energy transfer in chemistry might relate to biology, she seemed to be at a loss.

Louanne: I don't know if things happen the same way. Just because when I think of energy transferring in chemistry, I'm thinking of atoms colliding. And just because biology's just at a little bit bigger scale than the atoms colliding... I'm sure that in some way they do relate. Because, I mean the cells are made of atoms... So [pause] I think in some way that you could, but I don't know if I have.

Because biological systems are typically discussed at a larger scale than in chemistry, she had not considered the relevance of collisions in biology. While she recognized that the systems discussed in GC1/GC2 and B1 were related, it was not immediately apparent to her how to make those connections. Similarly, Evelyn could predict how collisions applied to biological systems, but she had not needed to make those connections for B1.

Evelyn: I might be wrong since we haven't talked about it, but I think it is collisions and things that make the process run. From step to step to step. We just kind of memorized the steps, what's formed in each step, and what's made in each step, or what's broken.

While in fact, her biology instructor did not require her to memorize the metabolic pathways, Evelyn chose to do so anyway. Her course did not consider the molecular-level interactions that allowed these reactions to occur, and she was unprepared to make those connections on her own without considerable prompting.

Opinions varied as to whether understanding the collisions associated with energy transfer would be helpful in biology. Some felt that energy transfer via collisions would be an unproductive addition to an already detailed course, or even that collisions were not applicable in biology. Others believed it might provide additional insight into how energy transfer occurs. Natalie was interested in trying to make connections between her courses but recognized it would be difficult.

Natalie: I think it would confuse me... Because in biology ... the systems of harvesting energy, it's a very long process. It's not just a collision ... you have a glucose molecule and it goes through this and then it goes through this and then it goes through this and then finally energy. You know, it's not just like, "Okay, two things collide and then your body interacts." So I think ... yeah, it would be an interesting thing to try to transfer over to my understanding of biology but I think it would be confusing at first.

Natalie believed that understanding energy transfer via collisions in the context of biology would be difficult by comparison, because there would be more than one collision to consider. Her implication being that, in chemistry, the focus is often on a single collision or within simple systems. While descriptions of a single collision were common in the context of disrupting or forming a stable interaction, there were also discussions of multiple, simultaneous collisions in the context of heating a container or in changes to the kinetics or equilibrium of a reaction (described earlier by both Louanne and Natalie). Despite this, Natalie still felt that the gap in complexity would be a difficult one to bridge on her own.

John felt that understanding energy transfer via collisions would not have helped him on his biology exams. However, he did value the time spent discussing energy transfer in chemistry, as it was something "you have to understand." When questioned about his ability to apply what he learned about energy transfer from chemistry to biology, John stated: "If I had to I could but I don't-there's no reason to... Because you don't go into the depth of it." In biology, only the presence of energy was mentioned, whereas they had discussed "how the energy would play a role in the reaction" in his chemistry course. So while he believed that he could apply his understanding of energy transfer to biology, he had not needed to do so. Despite this, John had faith that one day he would.

John: I imagine I'm going to have to at some point in time... I could see where it would be very important to understand energy and how it's transferred [in biology] because ... when you're talking about energy so much, you need to understand where it's coming from and where it's going. You can't just assume there's just energy floating out there and [it] just magically goes into something and then something happens... You have to understand why that energy's needed and how it's used.

John recognized the value of understanding energy transfer at the molecular level. Without it, he felt that you might take for granted energy's role in reactions, believing it just "magically" occurs. John was able to acknowledge these potential misconceptions because of his understanding of energy transfer from GC1/GC2.

John: I think you can understand biology without a chem background, but it's definitely nice to have a mix of all the chem stuff in there ... because the chem is just real in detail and like bio doesn't go into that much detail in like the chemistry side... So if you have the prior knowledge [from chemistry], you can apply that to what's going on in biology. But if you don't have the prior knowledge, you can't-you have nothing to work with.

John did believe that biology could be understood without a chemistry background, but he recognized that it would be a different depth of understanding. Ultimately, John represents a best-case scenario. He developed an understanding of the transfer of kinetic energy via collisions in GC1/GC2. And, even though it was not necessary for him to apply this understanding in B1, he believed that it was valuable information that would someday be necessary for him to think about in a biological context. Additionally, John was able to consider what might have happened if he had not understood the molecular-level mechanism of energy transfer; that he might have taken energy for granted and never considered why things occurred. He believed that, without the prior knowledge that he had built in chemistry, he would have had "nothing to work with" when attempting to understand the underlying molecular-level mechanism. Students' prior understanding of collisions was not well connected to their knowledge of energy in biology, resulting in a missed opportunity to make stronger connections between 
the disciplines. Only John appears to have fully recognized the potential of making such a connection.

Dynamic Nature of Biological Systems. Student descriptions of biological systems in the context of energy contain few references to the dynamic nature of the molecular-level and the kinetic energy transfers involved. In fact, not a single student explicitly referenced kinetic energy in the context of biology. The potential consequences of these descriptions are made most apparent by Clarice and Aaron who, when attempting to discuss the metabolic cycles, used neither reaction coupling nor collisions to describe a molecular-level mechanistic explanation.

Clarice associated energy transfer with the breaking and forming of bonds in a chemical reaction. However, when asked how energy transfer related to B1 she was tentative in her response, considering as she spoke.

Clarice: [It's] different than in chemistry ... the energy released in the one spot eventually I guess works itself down. You use ATP in glycolysis and it - that energy gets moved to the Krebs cycle ... and like gets transferred I guess, from everywhere... In biology I guess I think it has-when I think about it, it has [an] effect on a lot of different parts not just ... like in chemistry where I think of it as just having an effect on this one reaction.

Clarice was focused on describing the order of events (i.e., from glycolysis to the Krebs cycle) and the increased complexity of biological systems in comparison with the ones discussed in chemistry. Her focus on the differences between the systems may have resulted in her belief that energy transfer was different depending on the disciplinary context. When asked to describe how the energy transfer in biology occurs, her response focused on biological pathways.

Clarice: In bio, and I think it's because the one energy released, it goes down the chain of events. I know it goes from this cycle to this cycle to this cycle, that's the natural occurrence. So I think the energy just flows through.

Clarice has been taught the metabolic pathways in a particular order and how the products of one pathway feed into the next. However, her description indicates that she has taken this process for granted as the "natural occurrence." Clarice was unable to describe how this occurred, instead stating that she was just told that it happened. This is in direct contrast to her identification of an explicit, molecular-level description of how kinetic (though not potential) energy transfers in chemistry: "through [atoms] hitting each other." She went on to state that this idea of atoms or molecules colliding to transfer energy does not apply to biology. In this way, Clarice's understanding of bond energies and collisions does not appear to have been connected to her understanding of energy in biological systems.

Similarly, Aaron brought up collisions as something he learned in GC1/GC2. However, he did not give the same attention to the molecular level when discussing biological systems. Instead, he too described energy transfer between metabolic cycles. "If energy is given off by some system ... it somehow needs to get the energy back. I think of it more as a cycle thing in bio, because a lot of the processes are repetitive within your body." Aaron's regular use of the term "cycle" and his statement that the energy lost will need to be renewed would suggest that he understands that energy must be consistently added to metabolic processes, but later he contradicts this view.

Aaron: I see bio as more of a cycled aspect of energy. I think if something is continuously going around and around and around ... the system is not going to lose energy and it's not going to gain energy. It's just going to keep going on what it has.

Aaron's description of energy in the context of biological systems was certainly inconsistent, and while it is unlikely that he really does think that the energy is continuously being recycled without being gained or lost, he goes on to state that he does not need to worry about energy transfer, because the energy is already there.

Aaron: We know that these processes happen. And I think of energy as a more continuous cycle, so you don't need to worry about energy being transferred at all... That's just how I think about it, how it's cycled through. I think of it more as it already has energy. Energy is being transferred, but I already see it as it's already there... I don't care where it's coming from.

His matter-of-fact view of these processes allowed him to believe that energy transfer was unimportant and that he could take it for granted, that energy would be present whenever needed. And yet, when asked to consider his understanding of energy in both courses, Aaron asserted that he could apply what he learned about energy in chemistry to biological systems.

Aaron: I can make sense of it through chemistry. I know that this energy came from somewhere; it didn't just come out of nowhere. I know that it's continuously being transferred. Like I said in the earlier questions, the fact that I learned it here [in chemistry] makes me better understand it here [in biology].

Having discussed energy transfer and the conservation of energy in GC1/GC2, Aaron recognized that these same principles apply to biological systems. However, it was not clear that he could appropriately discuss or use them. Although Clarice recognized that energy transfer could occur via collisions, neither Aaron nor Clarice provided a description of energy transferring via collisions or reaction coupling in biological systems. Instead, both students appear complacent with their level of understanding of energy in biology. However, as John stated, "You can't just assume there's just energy floating out there and [it] just magically goes into something and then something happens... You have to understand why that energy's needed and how it's used."

\section{DISCUSSION}

What stands out most dramatically is the context dependence of students' descriptions of energy. While students recognized the general importance of energy to the scientific world, nine felt that energy was more important to understand in GC1/GC2 than B1. We found that student discussions of ATP were often oversimplified (i.e., five students referred to ATP as energy or a 
form of energy) and eight students expressed confusion as to how ATP works. Additionally, reaction coupling was only discussed by two students. In comparison, most students were able to discuss the foundational energy topics that had been presented in GC1/GC2, such as potential energy (11 of 14), the relationship between energy and the breaking and forming of bonds (12 of 14), and kinetic energy transfer via collisions (10 of 14). However, in many cases, this approach to understanding energy transfer and bond breaking/forming did not appear to be useful to students in B1. Five students believed there to be a conflict between how their courses presented the relationship between energy and the breaking/forming of bonds. Only two students discussed potential energy in the context of biology. And opinions on the relevance of collisions to their biology content ranged widely. Together, students' discussions of the perceived importance of energy within their courses, the various mechanisms of energy transfer discussed, and their own understanding of the relationship between energy and the breaking/ forming of bonds reveal a profound difference between how energy was presented and used in their course work, and their perceptions of what was or was not important clearly factored into whether they chose to use their prior knowledge.

In chemistry, energy was embedded in the progression of topics, necessary for building understanding throughout the course. As Daniel said, "In chemistry, in order to succeed and learn the next idea, big concept or whatever you need to know, that you need to know about energy." In biology, energy was also considered fundamental; life could not exist without it. And yet, students felt that the discussion of energy was limited to metabolic cycles and did not recognize it as a lens through which many of the ideas they were learning could be considered. Generally, students perceived energy to be more important in GC1/GC2, necessary for success and to achieve a strong understanding of the material. Whereas in biology, this was not the case; Natalie even went so far as to note that "I think you can still do well on any biology test that I've taken without really understanding energy and its properties." This idea that course assessments tend to drive what students focus on has been noted on many occasions (Snyder, 1970; Crooks, 1988; Entwistle, 1991; Scouller and Prosser, 1994; Scouller, 1998; Momsen et al., 2013) and is consistent with one of the tenets of meaningful learning - that is, students have to choose to incorporate new knowledge into existing cognitive structures (Ausubel, 1968; Novak, 1998). If assessment practices do not encourage such behavior, students may not see the value of putting in the effort to learn meaningfully. GC1/GC2 and B1 both acknowledged the importance of energy, each explicitly identifying it as a core idea. However, the core ideas were incorporated into these courses differently. While GC1/GC2 was redesigned from the ground up to help students understand and connect the core ideas throughout the course (Cooper and Klymkowsky, 2013a; Cooper et al., 2017), efforts to transform B1 were still in the early stages. The core ideas, negotiated by the B1 instructors, were explicitly incorporated into lecture, but the commercial textbook and homework system did not appear to reinforce them, instead focusing on particular topics around which the units were organized. And so, it is unsurprising that students recognized these differences.

Students' ideas about energy transfer and the energy associated with bond breaking/forming were more confidently expressed in the context of GC1/GC2. Of the 14 students interviewed, all 12 who discussed the relationship between energy and the breaking/forming of bonds in the context of chemistry did so correctly (i.e., that breaking bonds requires energy and forming bonds releases energy), but did not explicitly connect this to potential energy transfer. Collisions were described as the mechanism of energy transfer learned in chemistry by 10 of the 14 students. Both ideas were discussed extensively and explicitly throughout the two-semester general chemistry course sequence. And yet, some students did not see the need to apply their ideas to B1 (e.g., John), and others explicitly stated that their courses were providing conflicting information about the relationship between energy and the breaking/forming of bonds. For Lida and Priyah, this dichotomy resulted in the pragmatic decision to provide the "correct" (expected) answer in each course. However, others (like Daniel) expressed a desire for stronger connections to be made between their courses. Students with an interest and intellectual curiosity about science were certainly not being satisfied by the explanations provided. Indeed, even those pragmatists who could "play the game" and return what was expected were being provided with the antithesis of a scientific message. While there are certainly differences in the ways that chemistry and biology (and other STEM disciplines) approach energy concepts, it should give us all pause to think about the messages we send when we do not address those differences. Ausubel (1968) discussed a similarly problematic practice among textbook writers that involved the compartmentalization of common concepts into topical chapters and the subsequent assumption that students were capable of and would chose to perform the necessary "cross-referencing" to make meaningful connections. As he pointed out, if "little serious effort is made explicitly to explore relationships between these ideas, to point out significant similarities and differences, and to reconcile real or apparent inconsistencies," students may be driven to rote learning, and "artificial barriers" may obscure common features (Ausubel, 1968, p. 155). Students (e.g., Lida and Priyah) who chose to memorize the correct answer in each course may have been driven to such rote learning by the "cognitive strain and confusion" associated with making the necessary connections between their chemistry and biology understanding on their own (Ausubel, 1968; Cooper et al., 2017).

When considering the learning objectives of both courses, it is clear that there is a common goal-to develop a useful and transferable understanding of energy. And yet, neither course appeared to provide students with appropriate activities, knowledge, and explanations to meet these expectations. When discussing chemical systems, those interviewed could describe collisions transferring kinetic energy in the context of a phase change or the breaking/forming of bonds. However, these same students were not able to provide coherent explanations about how potential energy is transferred via coupled reactions. In biological systems students described energy as ATP, cycling through metabolic pathways. However, they were not clear about the mechanism by which energy transfer was occurring. In fact, as Aaron seemed to indicate, there was no need to consider such a mechanism: "We know that these processes happen. And I think of energy as a more continuous cycle, so you don't need to worry about energy being transferred at all." 
While students appeared to have a grasp of how kinetic energy is transferred in chemistry, these ideas were simply not applied in the context of biology. And the mechanism by which potential energy is transferred was less clear both in chemistry and biology. As the K-12 system continues to be transformed in the context of the Next Generation Science Standards (NGSS Lead States, 2013), students will be entering college with an understanding of potential and kinetic energy as the two forms of energy. It will be important for them to be able to extend these ideas to how energy is transferred at the molecular level, both by collisions (kinetic energy) and the formation of stronger bonds replacing weaker ones, in the context of coupled reactions (potential energy). Indeed, it is clear that we are not providing a coherent and universally applicable description of the mechanisms by which energy is transferred in either course. Students who have been educated using the vision of the Framework will have been exposed to crosscutting concepts such as "cause and effect: mechanism and explanation" (NRC, 2012). If we open the door to mechanistic thinking, we need to be prepared to respond. We must recognize that compatible mechanistic explanations of kinetic and potential energy transfer must transcend common disciplinary practices (or shortcuts).

The literature has clearly shown that the belief that breaking bonds releases energy is problematic and resistant to change (Storey, 1992; Boo, 1998; Barker and Millar, 2000; Teichert and Stacy, 2002; Galley, 2004). Our work demonstrates that even students with a strong understanding of the relationship between energy and the breaking/forming bonds in one discipline have difficulty transferring that understanding in a coherent manner when situated in the context of another. While these students theoretically might have been prepared for future learning (Bransford and Schwartz, 1999), in this situation, they certainly were unable to activate this knowledge. Providing a description of the hydrolysis of ATP as the source of energy can lead students to believe that they are being told by their instructor that breaking bonds releases energy, which may give the impression that their instructors are presenting contradictory information. Not only is this confusing to students, but it reinforces the idea that the science disciplines are separate and that their understanding should be compartmentalized. This is in direct conflict with our goal of helping students develop a consistent, useful, and transferable set of knowledge and skills. To this end, it is the responsibility of both chemistry and biology instructors to address the mechanisms of energy transfer such that students can develop a coherent understanding that can be applied across disciplinary contexts.

Some may argue that such an explanation is rightfully addressed in more advanced biology courses (e.g., biochemistry), when students are expected to have sufficient prior knowledge in reaction kinetics and thermodynamics to engage with this explanation at a conceptual level. However, this would require students to recall information taught in a chemistry course 2 years prior (in many cases) and transfer that understanding to a biological context that they may or may not recognize as similar. Additionally, those who do not take upper-level courses may end up leaving college with a confused understanding of energy in biological systems (Villafañe et al., 2011).

\section{IMPLICATIONS FOR TEACHING}

It is unsurprising that students' experiences with energy differed between these two courses (disciplines), given that each has different objectives and considers systems of vastly different complexities and characteristics. GC1/GC2 is a service course meant to help students with many academic backgrounds develop an understanding of chemistry that can serve as the foundation for more advanced science courses in various disciplines. In comparison, a substantial portion of the students who take B1 are biology or pre-professional majors with the intention of taking more advanced biology course work for which this course must prepare them. Additionally, chemical systems begin at a distinct moment and move toward a stable equilibrium, whereas biological systems have an origin in the distant past, have a history, and maintain a nonequilibrium state. Based on these differences in both course goals and disciplinary perspectives, the significance of particular concepts (such as energy) are likely to change. A typical biology course may never explicitly consider the role of energy inputs in terms of molecular synthesis and associated repair and replacement mechanisms or macroscopic phenomena such as movement and growth. It is for this reason that it is critical that students' introductory science instructors work together to build and connect student understanding into a coherent whole. To do so effectively, especially in the case of a concept so important and yet perpetually confusing as energy, we must consider not just the perspective and goals of our own discipline, but those of the other sciences. As students are often enrolled in introductory chemistry courses before cell and molecular biology, it is the responsibility of chemistry instructors to effectively prepare students to understand energy in biological systems. Chi and VanLehn (2012) suggest that, in some cases, it may not be that knowledge transfer has failed to occur but that students have not sufficiently learned the material in the first place. That being said, our findings show that students' conceptual understanding of energy in one context does not automatically translate to other disciplinary contexts. In this case, we believe that students did not perceive a need to use their prior knowledge in the context of biology, and therefore were unable to use energy ideas in appropriate ways. One thing is clear, if we are to provide learning environments in which students are able make these connections, instructors must collaborate across disciplines to negotiate long-term learning goals for the students enrolled in their courses.

There are a number of potential approaches that could provide the basis for these conversations. One school of thought is that introductory biology instructors focus on thermodynamic connections between the courses. Rather than addressing the mechanism by which reaction coupling occurs, they would use thermodynamic factors such as Gibbs free energy change to indicate overall Gibbs energy changes for coupled reactions. To pursue this approach, instructors will need to consider how best to ensure that students have sufficient conceptual understanding of thermodynamics to engage with such a discussion in biological systems, particularly in light of the nonstandard conditions found in living systems. This does remove the requirement for any discussion of molecular-level events, but for many molecular biology introductory courses that purposefully include molecular-level mechanistic reasoning, this approach may not be a satisfactory solution. 
Another potential approach is to restructure the introductory chemistry and biology courses around common themes, such as energy or the relationship between structure, properties, and function. Certainly, this is ambitious and may not be an option for all who wish to do so, as it would require significant buy-in across multiple departments and instructors. There are few examples of thematic reforms of chemistry and biology courses (Goldey et al., 2012; Schaller et al., 2014; Hunt, 2017), and while integrated courses that cross disciplinary boundaries do exist (Copp et al., 2012; Gentile et al., 2012; Lega et al., 2014; Johnson and Graves, 2017), the designs of such courses range widely, and the evidence of improved learning is sparse. Such courses provide an intriguing opportunity for education research, and we look forward to future studies on the effectiveness of such approaches for improving students' understanding of interdisciplinary concepts and their ability to make substantive connections across disciplines.

Given the findings presented here, our experience reforming how energy is taught in general chemistry (Cooper and Klymkowsky, 2013b; Cooper, 2015; Becker et al., 2016), and our interdisciplinary conversations about connections between chemistry and biology (Cooper et al., 2015; Klymkowsky et al., 2016), we advocate the potential of a third approach that builds on the approach developed in the Framework and involves treating energy as either potential or kinetic energy. We believe that a common discussion of kinetic and potential energy transfer via molecular-level collisions and reaction coupling, respectively, can serve as a bridge between the disciplines and allow students to make the connections that are so important. We provide a longer description of this approach and the ways in which both kinetic and potential energy transfer could be discussed in Appendices B and C in the Supplemental Material.

Regardless of the approach that is taken, without constructive conversations across the disciplines, it is unlikely that students will leave their introductory science courses with a coherent and productive understanding of energy. By negotiating long-term learning goals and understanding the constraints and perspectives at play, instructors can work toward fostering a more cohesive, interdisciplinary learning environment. It will be important for both biology and chemistry instructors to understand what resources students are bringing with them from chemistry to support the relevant parts of the biology curriculum. For example, closer communication might allow instructors to explicitly ask students to connect ideas across disciplines. If courses are restructured to emphasize core ideas and crosscutting concepts, then students can be helped to make these connections. This is especially important in instances in which such connections are not immediately obvious - and it is clear that these connections are particularly problematic for students attempting to understand energy. One way that this could be undertaken is by scaffolding activities to require students to think about content and examples learned in other courses. In chemistry courses, this may be through the inclusion of systems that introductory biology instructors will teach in more detail. For biology instructors, this may be the inclusion of prompts asking students what prior knowledge they may bring to bear on the problem. Such activities could also be used to assess whether and how well students are able to bring in relevant concepts learned in other contexts. Certainly, it is likely that different learning environments (e.g., based on class size or students' academic backgrounds and goals) will require different approaches. Therefore, we strongly encourage those considering such reforms to collect evidence on the efficacy of their approaches.

\section{LIMITATIONS OF THE STUDY}

The students who were interviewed in this study were concurrently enrolled in chemistry and biology courses that had been transformed in light of the education research literature. As previously noted, these courses were not at the same stage of transformation, but nevertheless, both courses were undergoing transformation efforts. These contextual details may have influenced student understanding and descriptions of energy in chemical and biological systems. And therefore, students situated in other, more traditional learning environments would likely not respond in the same ways. It is not our intention to infer that these students' experiences could be generalized to other science classrooms. However, it is notable that, even in situations in which transformational efforts have been made to improve student understanding of energy, more work needs to be done to help students make connections across disciplinary boundaries.

\section{ACKNOWLEDGMENTS}

We thank Mike Klymkowsky, Cori Fata-Hartley, and Jon Stoltzfus for very helpful discussions. This work was supported in part by the Association of American Universities' (AAU) Undergraduate STEM Education Initiative, funded by the Helmsley Charitable Trust, and by the National Science Foundation under DUE 0816692 (1359818). Any opinions, findings, conclusions, or recommendations expressed here are those of the authors and do not necessarily reflect the views of the National Science Foundation.

\section{REFERENCES}

American Association for the Advancement of Science. (2011). Vision and change in undergraduate biology education: A call to action. Washington, DC.

Anderson, J. R., Reder, L. M., \& Simon, H. A. (1996). Situated learning and education. Educational Researcher, 25(4), 5-11.

Ausubel, D. P. (1960). The use of advance organizers in the learning and retention of meaningful verbal material. Journal of Educational Psychology, 51(5), 267-272.

Ausubel, D. P. (1968). Educational psychology: A cognitive view. New York: Holt, Rinehart, \& Winston.

Bain, K., Moon, A., Mack, M. R., \& Towns, M. H. (2014). A review of research on the teaching and learning of thermodynamics at the university level. Chemistry Education Research and Practice, 15, 320-335. https:// doi.org/10.1039/C4RP00011K

Banerjee, A. C. (1995). Teaching chemical equilibrium and thermodynamics in undergraduate general chemistry classes. Journal of Chemical Education, 72, 879-881.

Barak, J., Gorodetsky, M., \& Chipman, D. (1997). Understanding of energy in biology and vitalistic conceptions. International Journal of Science Education, 19, 21-30. https://doi.org/10.1080/0950069970190102

Barker, V., \& Millar, R. (2000). Students' reasoning about basic chemical thermodynamics and chemical bonding: What changes occur during a context-based post-16 chemistry course? International Journal of Science Education,22,1171-1200.https://doi.org/10.1080/09500690050166742.

Barnett, S. M., \& Ceci, S. J. (2002). When and where do we apply what we learn? A taxonomy for far transfer. Psychological Bulletin, 128(4), 612. 
Batiza, A. F., Gruhl, M., Zhang, B., Harrington, T., Roberts, M., LaFlamme, D., ... Nelson, D. (2013). The effects of the SUN project on teacher knowledge and self-efficacy regarding biological energy transfer are significant and long-lasting: Results of a randomized controlled trial. CBE-Life Sciences Education, 12(2), 287-305. https://doi.org/10.1187/cbe.12-09-0155

Beach, K. (1999). Consequential transitions: A sociocultural expedition beyond transfer in education. Review of Research in Education, 24, 101-139.

Beach, K. (2003). Conceptualizing transfer: From standard notions to developmental perspectives. In Tuomi-Gröhn, T., \& Engeström, Y. (Eds.), Between school and work: New perspectives on transfer and boundary-crossing (pp. 39-62). Amsterdam, Netherlands: Pergamon.

Becker, N. M., \& Cooper, M. M. (2014). College chemistry students' understanding of potential energy in the context of atomic-molecular interactions. Journal of Research in Science Teaching, 51(6), 789-808. https:// doi.org/10.1002/tea.21159

Becker, N. M., Noyes, K., \& Cooper, M. M. (2016). Characterizing students' mechanistic reasoning about London dispersion forces. Journal of Chemical Education, 93(10), 1713-1724.

Boo, H. K. (1998). Students' understandings of chemical bonds and the energetics of chemical reactions. Journal of Research in Science Teaching, 35, 569-581.

Bransford, J. D., \& Schwartz, D. L. (1999). Chapter 3: Rethinking transfer: A simple proposal with multiple implications. Review of Research in Education, 24(1), 61-100

Brown, M. H., \& Schwartz, R. S. (2009). Connecting photosynthesis and cellular respiration: Preservice teachers' conceptions. Journal of Research in Science Teaching, 46, 791. https://doi.org/10.1002/tea.20287

Butterfield, E. C., \& Nelson, G. D. (1991). Promoting positive transfer of different types. Cognition and Instruction, 8(1), 69-102.

Carraher, D., \& Schliemann, A. (2002). The transfer dilemma. Journal of the Learning Sciences, 11(1), 1-24.

Carson, E. M., \& Watson, J. R. (1999). Undergraduate students' understanding of enthalpy change. University Chemistry Education, 3, 46-51.

Carson, E. M., \& Watson, J. R. (2002). Undergraduate students' understandings of entropy and Gibbs free energy. University Chemistry Education, 6 , 4-12.

Cell Energy and Cell Functions (n.d.). Nature Education. Retrieved March 7, 2017, from www.nature.com/scitable/topicpage/cell-energy-and-cell -functions-14024533

Chabalengula, V. M., Sanders, M., \& Mumba, F. (2012). Diagnosing students understanding of energy and its related concepts in biological context. International Journal of Science and Mathematics Education, 10, $241-$ 266.

Chen, R. F., Eisenkraft, A., Fortus, D., Krajcik, J. S., Neumann, K., Nordine, J., \& Scheff, A. (2014). Teaching and learning of energy in $K-12$ education. New York: Springer.

Chi, M. T., \& VanLehn, K. A. (2012). Seeing deep structure from the interactions of surface features. Educational Psychologist, 47(3), 177-188.

College Board (2014). AP chemistry course and exam description (Rev. ed.). Retrieved November 18, 2016, from https://apcentral.collegeboard.com

Cooper, M. M. (2015). Why ask why? Journal of Chemical Education, 92, 1273-1279. https://doi.org/10.1021/acs.jchemed.5b00203

Cooper, M. M., Caballero, M. D., Ebert-May, D., Fata-Hartley, C. L., Jardeleza, S. E., Krajcik, J. S., ... Underwood, S. M. (2015). Challenge faculty to transform STEM learning. Science, 350(6258), 281-282. https://doi.org/10.1126/ science.aab0933

Cooper, M. M., \& Klymkowsky, M. W. (2013a). Chemistry, Life, the Universe and Everything: A new approach to general chemistry, and a model for curriculum reform. Journal of Chemical Education, 90, 1116-1122. https://doi.org/10.1020/ed300456y

Cooper, M. M., \& Klymkowsky, M. W. (2013b). The trouble with chemical energy: Why understanding bond energies requires an interdisciplinary systems approach. CBE-Life Sciences Education, 12, 306-312. https:// doi.org/10.1187/cbe.12-10-0170

Cooper, M. M., Klymkowsky, M. W., \& Becker, N. M. (2014). Energy in chemical systems: An integrated approach. In Chen, R. F., Eisenkraft, A., Fortus, D., Krajcik, J. S., Neumann, K., Nordine, J., \& Scheff, A. (Eds.) Teaching and learning of energy in $K-12$ education (pp. 301-316). New York: Springer
Cooper, M. M., Posey, L. A., \& Underwood, S. M. (2017). Core ideas and topics: Building up or drilling down? Journal of Chemical Education, 94(5), 541-548. https://doi.org/10.1021/acs.jchemed.6b00900

Copp, N. H., Black, K., \& Gould, S. (2012). Accelerated Integrated Science Sequence: An interdisciplinary introductory course for science majors. Journal of Undergraduate Neuroscience Education, 11(1), A76-A81.

Crooks, T. J. (1988). The impact of classroom evaluation practices on students. Review of Educational Research, 58(4), 438-481.

Detterman, D. K. (1993). The case for the prosecution: Transfer as an epiphenomenon. In Detterman, D. K., \& Sternberg, R. J. (Eds.), Transfer on trial: Intelligence, cognition, and instruction (pp. 1-24). Norwood, NJ: Ablex.

Dreyfus, B. W. (2014). Interdisciplinary reasoning about energy in an introductory physics course for the life sciences. College Park: University of Maryland. Retrieved from https://drum.lib.umd.edu/handle/1903/15339

Dreyfus, B. W., Gouvea, J., Geller, B. D., Sawtelle, V., Turpen, C., \& Redish, E. F. (2014). Chemical energy in an introductory physics course for the life sciences. American Journal of Physics, 82, 403-411. https://doi.org/ 10.1119/1.4870391

Energy. (2000). Encyclopaedia Britannica. Retrieved March 7, 2017, from www britannica.com/science/energy

Entwistle, N. J. (1991). Approaches to learning and perceptions of the learning environment. Higher Education, 22(3), 201-204.

Feynman, R. P., Leighton, R. B., \& Sands, M. (1977). The Feynman Lectures on physics (Desktop ed.) (Vol. 1). Boston, MA: Addison Wesley.

Fortus, D., Krajcik, J., Dershimer, R. C., Marx, R. W., \& Mamlok-Naaman, R. (2005). Design-based science and real-world problem-solving. International Journal of Science Education, 27(7), 855-879.

Fortus, D., Sutherland Adams, L. M., Krajcik, J. S., \& Reiser, B. (2015). Assessing the role of curriculum coherence in student learning about energy. Journal of Research in Science Teaching, 52, 1408-1425. https://doi.org/ 10.1002/tea.21261

Galley, W. C. (2004). Exothermic bond breaking: A persistent misconception. Journal of Chemical Education, 81, 523-526. https://doi.org/10.1021/ ed081p523

Garvin-Doxas, K., \& Klymkowsky, M. W. (2008). Understanding randomness and its impact on student learning: Lessons learned from building the Biology Concept Inventory (BCI). CBE-Life Sciences Education, 7, 227233. https://doi.org/10.1187/cbe.07-08-0063

Gayford, C. G. (1986). Some aspects of the problems of teaching about energy in school biology. European Journal of Science Education, 8, 443450. https://doi.org/10.1080/0140528860080410

Geller, B. D. (2014). Explanatory coherence in the context of the second law of thermodynamics (Doctoral dissertation). College Park: University of Maryland. Retrieved October 18, 2016, from https://drum.lib.umd.edu/ handle/1903/16203

Geller, B. D., Dreyfus, B. W., Gouvea, J., Sawtelle, V., Turpen, C., \& Redish, E. F. (2014). Entropy and spontaneity in an introductory physics course for life science students. American Journal of Physics, 82(5), 394-402. https:// doi.org/10.1119/1.4870389

Gentile, L., Caudill, L., Fetea, M., Hill, A., Hoke, K., Lawson, B., ... Szajda, D. (2012). Challenging disciplinary boundaries in the first year: A new introductory integrated science course for STEM majors. Journal of College Science Teaching, 41(5), 44.

Goldey, E. S., Abercrombie, C. L., Ivy, T. M., Kusher, D. I., Moeller, J. F., Rayner, D. A., ... Spivey, N. W. (2012). Biological inquiry: A new course and assessment plan in response to the call to transform undergraduate biology. CBE-Life Sciences Education, 11(4), 353-363.

Goldring, H., \& Osborne, J. (1994). Students' difficulties with energy and related concepts. Physics Education, 29, 26-31. https://doi.org/10.1088/ 0031-9120/29/1/006.

Gonzales, A. O. (2011). Assessment of conceptual understanding of atomic structure, covalent bonding, and bond energy (Master's thesis). Clemson, SC: Clemson University. Retrieved October 12, 2016, from https:// tigerprints.clemson.edu/all_theses/1109/

Greenbowe, T. J., \& Meltzer, D. E. (2003). Student learning of thermochemical concepts in the context of solution calorimetry. International Journal of Science Education, 25, 779-800. https://doi.org/10.1080/ 09500690305032 
Greeno, J. G. (1997). On claims that answer the wrong questions. Educational Researcher, 26(1), 5-17.

Hadfield, L. C., \& Wieman, C. E. (2010). Student interpretations of equations related to the first law of thermodynamics. Journal of Chemical Education, 87, 750-755. https://doi.org/10.1021/ed1001625

Halpern, D. F. (1998). Teaching critical thinking for transfer across domains: Disposition, skills, structure training, and metacognitive monitoring American Psychologist, 53(4), 449.

Hecht, E. (2007). Energy and change. Physics Teacher, 45, 88-92. https:// doi.org/10.1119/1.2432084

Holme, T., Luxford, C., \& Murphy, K. (2015). Updating the general chemistry anchoring concepts content map. Journal of Chemical Education, 92, 1115-1116. https://doi.org/10.1021/ed500712k

Hunt, April (2017, September 11). Chemistry synthesizes radical overhaul of undergraduate curriculum. Emory News Center. Retrieved September 29, 2017, from https://news.emory.edu/

Jewett, J. W. Jr. (2008). Energy and the confused student III: Language Physics Teacher, 46, 149-153. https://doi.org/10.1119/1.2840978

Jin, H., \& Anderson, C. W. (2012). A learning progression for energy in socioecological systems. Journal of Research in Science Teaching, 49, 1149 1180. https://doi.org/10.1002/tea.21051

Johnson, A. F., \& Graves, C. W. (2017). What makes us who we are? Investigating the chemistry behind genetics in an interdisciplinary course for undergraduate students. Journal of College Science Teaching, 46(3), 19.

Kaper, W. H., \& Goedhart, M. J. (2002). "Forms of energy," an intermediary language on the road to thermodynamics? Part I. International Journal of Science Education, 24, 81-95. https://doi.org/10.1080/ 09500690110049114

Klymkowsky, M. W., Rentsch, J. D., Begovic, E., \& Cooper, M. M. (2016). The design and transformation of Biofundamentals: A nonsurvey introductory evolutionary and molecular biology course. CBE-Life Sciences Education, 15(4), ar70.

Lancor, R. A. (2014). Using student-generated analogies to investigate conceptions of energy: A multidisciplinary study. International Journal of Science Education, 36, 1-23. https://doi.org/10.1080/09500693.2012.714512

Lave, J. (1988). Cognition in practice: Mind, mathematics and culture in everyday life. Cambridge, UK: Cambridge University Press.

Lee, H.-S., \& Liu, O. L. (2010). Assessing learning progression of energy concepts across middle school grades: The knowledge integration perspective. Science Education, 94, 665-688. https://doi.org/10.1002/sce.20382

Lega, J. C., Buxner, S., Blonder, B., \& Tama, F. (2014). Explorations in integrated science. Journal of College Science Teaching, 43(4), 55-60.

Lehrman, R. L. (1973). Energy is not the ability to do work. Physics Teacher, 11, 15-18. https://doi.org/10.1119/1.2349846

Liu, X., \& McKeough, A. (2005). Developmental growth in students' concept of energy: Analysis of selected items from the TIMSS database. Journal of Research in Science Teaching, 42, 493-517. https://doi.org/10.1002/ tea. 20060

Lobato, J. (2003). How design experiments can inform a rethinking of transfer and vice versa. Educational Researcher, 32(1), 17-20.

Lobato, J. (2006). Alternative perspectives on the transfer of learning: History, issues, and challenges for future research. Journal of the Learning Sciences, 15(4), 431-449.

Lobato, J. (2012). The actor-oriented transfer perspective and its contributions to educational research and practice. Educational Psychologist, 47(3), 232-247.

Loertscher, J., \& Minderhout, V. (2010). Foundations of biochemistry (2nd ed.). Lisle, IL: Pacific Crest.

Marton, F. (2006). Sameness and difference in transfer. Journal of the Learning Sciences, 15(4), 499-535.

Mason, K., Johnson, G., Losos, J., \& Singer, S. (2015). Understanding biology (1st ed.). New York: McGraw-Hill Education.

Mayer, R. E. (1999). Multimedia aids to problem-solving transfer. International Journal of Educational Research, 31(7), 611-623.

Momsen, J., Offerdahl, E., Kryjevskaia, M., Montplaisir, L., Anderson, E., \& Grosz, N. (2013). Using assessments to investigate and compare the nature of learning in undergraduate science courses. CBE-Life Sciences Education, 12(2), 239-249. https://doi.org/10.1187/cbe.12-08-0130
National Research Council. (2012). A framework for $K-12$ science education: Practices, crosscutting concepts, and core ideas. Washington, DC: National Academies Press

Neumann, K., Viering, T., Boone, W. J., \& Fischer, H. E. (2013). Towards a learning progression of energy. Journal of Research in Science Teaching, 50, 162-188. https://doi.org/10.1002/tea.21061

Next Generation Science Standards Lead States. (2013). Next generation science standards: For states, by states. Washington, DC: National Academies Press. Retrieved March 6, 2017, from www.nextgenscience.org/ ngss-high-school-evidence-statements

Nilsson, T., \& Niedderer, H. (2012). An analytical tool to determine undergraduate students' use of volume and pressure when describing expansion work and technical work. Chemistry Education Research and Practice, 13, 348-356. https://doi.org/10.1039/C2RP20007D

Nilsson, T., \& Niedderer, H. (2014). Undergraduate students' conceptions of enthalpy, enthalpy change and related concepts. Chemistry Education Research and Practice, 15, 336-353. https://doi.org/10.1039/C2RP20135F

Nordine, J. (Ed.). (2015). Teaching energy across the sciences, $K-12$. Arlington, VA: National Science Teachers Association.

Novak, J. D. (1977). A theory of education. Ithaca, NY: Cornell University Press.

Novak, J. D. (1998). Learning, creating, and using knowledge: Concept maps as facilitative tools in schools and corporations. Mahwah, NJ: Erlbaum.

Novak, J. D. (2002). Meaningful learning: The essential factor for conceptual change in limited or inappropriate propositional hierarchies leading to empowerment of learners. Science Education, 86, 548-571.

Novick, L. R. (1988). Analogical transfer, problem similarity, and expertise. Journal of Experimental Psychology: Learning, Memory, and Cognition, 14(3), 510

Ogborn, J. (1986). Energy and fuel: The meaning of "the go of things." School Science Review, 68(242), 30-35.

Ogborn, J. (1990). Energy, change, difference and danger. School Science Review, 72(259), 81-85.

Packer, M. (2001). The problem of transfer, and the sociocultural critique of schooling. Journal of the Learning Sciences, 10(4), 493-514

Papadouris, N., Constantinou, C. P., \& Kyratsi, T. (2008). Students' use of the energy model to account for changes in physical systems. Journal of Research in Science Teaching, 45, 444-469. https://doi.org/10.1002/tea.20235

Park, M., \& Liu, X. (2016). Assessing understanding of the energy concept in different science disciplines. Science Education, 100(3), 483-516. https://doi.org/10.1002/sce.21211

Parker, J. M., Anderson, C. W., Heidemann, M., Merrill, J., Merritt, B., Richmond, G., \& Urban-Lurain, M. (2012). Exploring undergraduates understanding of photosynthesis using diagnostic question clusters. CBE-Life Sciences Education, 11(1), 47-57. https://doi.org/10.1187/ cbe.11-07-0054

Perkins, D. N., \& Salomon, G. (1988). Teaching for transfer. Educational Leadership, 46(1), 22-32.

Pintó, R., Couso, D., \& Gutierrez, R. (2005). Using research on teachers transformations of innovations to inform teacher education. The case of energy degradation. Science Education, 89, 38-55. https://doi.org/ 10.1002/sce.20042

Redish, E. F., Bauer, C., Carleton, K. L., Cooke, T. J., Cooper, M. M., Crouch, C. H., ... Zia, R. K. P. (2014). NEXUS/Physics: An interdisciplinary repurposing of physics for biologists. American Journal of Physics, 82(5), 368-377. https://doi.org/10.1119/1.4870386

Schaller, C. P., Graham, K. J., Johnson, B. J., Fazal, M. A., Jones, T. N., Mclntee E. J., \& Jakubowski, H. V. (2014). Developing and implementing a reorganized undergraduate chemistry curriculum based on the foundational chemistry topics of structure, reactivity, and quantitation. Journal of Chemical Education, 91(3), 321-328.

Schwartz, D. L., \& Martin, T. (2004). Inventing to prepare for future learning: The hidden efficiency of encouraging original student production in statistics instruction. Cognition and Instruction, 22(2), 129-184.

Scouller, K. (1998). The influence of assessment method on students' learning approaches: Multiple choice question examination versus assignment essay. Higher Education, 35(4), 453-472.

Scouller, K. M., \& Prosser, M. (1994). Students' experiences in studying for multiple choice question examinations. Studies in Higher Education, 19(3), 267-279 
Sexl, R. U. (1981). Some observations concerning the teaching of the energy concept. European Journal of Science Education, 3, 285-289. https:// doi.org/10.1080/0140528810030305

Singley, M. K., \& Anderson, J. R. (1989). The transfer of cognitive skill. Cambridge, MA: Harvard University Press.

Snyder, B. R. (1970). The hidden curriculum. Retrieved August 9, 2017, from https://philpapers.org/rec/SNYTHC

Storey, R. D. (1992). Textbook errors and misconceptions in biology: Cell energetics. American Biology Teacher, 54, 161-166. https://doi.org/ 10.2307/4449438

Teichert, M. A., \& Stacy, A. M. (2002). Promoting understanding of chemical bonding and spontaneity through student explanation and integration of ideas. Journal of Research in Science Teaching, 39, 464-496. https:// doi.org/10.1002/tea.10033.

Trumper, R. (1990a). Being constructive: An alternative approach to the teaching of the energy concept-part one. International Journal of Science Education, 12, 343-354. https://doi.org/10.1080/0950069900120402

Trumper, R. (1990b). Energy and a constructivist way of teaching. Physics Education, 25, 208. https://doi.org/10.1088/0031-9120/25/4/306
Trumper, R. (1991). Being constructive: An alternative approach to the teaching of the energy concept-part two. International Journal of Science Education, 13, 1-10. https://doi.org/10.1080/0950069910130101

Tuomi-Gröhn, T., \& Engeström, Y. (2003). Conceptualizing transfer: From standard notions to developmental perspectives. In Tuomi-Gröhn, T., \& Engeström, Y. (Eds.), Between school and work: New perspectives on transfer and boundary-crossing (pp. 19-38). Amsterdam, Netherlands: Pergamon.

Villafañe, S. M., Loertscher, J., Minderhout, V., \& Lewis, J. E. (2011). Uncovering students' incorrect ideas about foundational concepts for biochemistry. Chemistry Education Research and Practice, 12(2), 210-218.

Wagner, J. F. (2010). A transfer-in-pieces consideration of the perception of structure in the transfer of learning. Journal of the Learning Sciences, 19(4), 443-479.

Watts, D. M. (1983). Some alternative views of energy. Physics Education, 18 213-217. https://doi.org/10.1088/0031-9120/18/5/307

Wilson, C. D., Anderson, C. W., Heidemann, M., Merrill, J. E., Merritt, B. W. Richmond, G., ... Parker, J. M. (2006). Assessing students' ability to trace matter in dynamic systems in cell biology. Cell Biology Education, 5, 323-331. https://doi.org/10.1187/cbe.06-02-0142 